\title{
Analysis of welding properties using various horn-tip patterns in the ultrasonic metal welding process
}

\author{
Jisun Kim, Jeawoong Kim", and Inju Kim \\ Smart Manufacturing Process R\&D Group, Korea Institute of Industrial Technology, Gwangju 61012, Korea
}

Received: 21 February 2019 / Accepted: 28 October 2019

\begin{abstract}
The present study was conducted to investigate how the characteristics of welds are affected by the horn-tip pattern shape, in order to assess how to efficiently transfer the vibration energy to a base material through the horn. Energy transfer was evaluated using the indentation marks. The experiment was carried out with aluminum and copper by combining the conditions from four horn-tip patterns, six pressure values, and ten welding time values. The aspect ratio of the indentation marks on the weld surfaces was measured. The effects of the applied pressure, welding time, and horn-tip pattern shape on the aspect ratio were analyzed, and it was found that the horn-tip pattern shape affects the aspect ratio significantly. The aspect ratio was suggested as an analytical reference, and its correlations with the shear strength and the hardness of the welds were verified. In addition, the experiment performed with aluminum and copper, which have different mechanical properties, under the same welding conditions showed that the aspect ratio was dependent on the mechanical properties of the materials. In conclusion, as the density of the horn-tip pattern is decreased, less of the vibration energy was lost, increasing the strength of the welds. Experimental results showed that shear strength of copper was nearly $400 \mathrm{~N}$ when the aspect ratio was close to the value of 1 . The highest peak of horn-tip pattern forms the lowest aspect ratio of the indentation mark, which can be indicated that the decrease of the aspect ratio effect to the improvement of welds strength. Aspect ratio of horn-tip pattern D, which dimensions are pitch $1.5 \mathrm{~mm}$, height $0.75 \mathrm{~mm}$ and stub tooth $0.7 \mathrm{~mm}$ was closely to the value of 1 compared to the other patterns.
\end{abstract}

Keywords: Ultrasonic welding / aluminum sheet / aspect ratio / copper sheet / horn-tip pattern / tensile shear strength

\section{Introduction}

The use of ultrasonic waves in the field of metalworking began in the latter half of the 20th century, and welding with initial ultrasonic waves was mainly used for bonding plastic. Ultrasonic welding has emerged as a bonding mechanism in the metal industry and has been applied to various applications until now $[1,2]$. Since the welding is performed through the diffusion of metal by vibration to remove an oxide film and impurities, the electric resistance is low, enabling the welding of nonferrous metals and dissimilar metals that are not easily welded through the conventional methods [3]. In addition, the welding time is very short, so the change in the physical properties of the weld metal is less than in other welding methods. For this reason, ultrasonic welding is generally used when welding a nickel tab and an aluminum foil of a battery pack or when welding a thin metal to multiple

\footnotetext{
* e-mail: kjw0607@kitech.re.kr
}

layers $[4,5]$. Ultrasonic welding is possible to weld at low temperatures, minimizing thermal deformation and thermal damage, to ensure the mechanical properties of the product and is economical because it does not require an additional filler metal [6-9]. Ultrasonic welding, which has been applied to thin plates of plastics or similar materials in the past, has been actively studied for non-ferrous metals as the manufacturing industry has become more lightweight in recent years[10]. Conductive materials such as copper, aluminum and nickel are widely used in the electronics industry. Recently, it has been adopted as electrode, current collector, and bus bar in the manufacture of lithium ion batteries for automobiles [11,12].

Research on ultrasonic welding of materials with high specific strength such as magnesium alloy and titanium alloy has been carried out by various researchers. Ren [13] reported metallographic studies of ultrasonic welds of different materials using magnesium and titanium alloys. $\mathrm{Ni}$ [14] adopted ultrasonic welding to weld aluminum and nickel, and conducted research to optimize welding conditions. The results of the study show that the strength 
of the joint decreases when the welding time limit is reached and the limitation of the welding condition range is explained. Many researchers have conducted research to optimize ultrasonic welding processes.

Ultrasonic welding processes are evolving in conjunction with traditional fusion welding processes such as laser welding, resistance spot welding and gas metal arc welding. $\mathrm{Li}$ [15] have reported that when aluminum and copper are welded by combining resistance spot welding and ultrasonic welding, the resistance heat at the contact surface increases and the intermetallic compound layer decreases. Lei [16] devised a method to reduce the porosity in the weld zone using ultrasonic vibration as an assistant for laser welding and obtained a uniform bead geometry.

Ultrasonic welding technology is continuously expanding its usage range. It has been applied to additive manufacturing (AM) technology, which is in recent demand $[17,18]$. Wu [19] fabricated Ni-based bulk metallic glasses using ultrasonic welding technology. Ni-based metal grass was continuously laminated and strengthened over the properties of the former metal grass. The most important technology in ultrasonic welding, which is being extended to various fields, is the ability to transmit vibration to the base metal. The shape of the horn that transmits the vibration generated by sonotrode to the base material is very important. The study on the shape of the horn was performed by computer-assisted method using FEM, and the optimal shape was derived [20]. The shape of the horn affects the natural frequency and range of vibration. When the shape of the horn is optimized, it is made of titanium material (Ti-6Al-4V) which can transmit vibration without loss. Many studies have optimized the shape of horns through analytical or experimental techniques [21-23]. The majority of those findings and relates to a horn shape (cylindrical, square, multi-stage type), it lacks the study on the shape of the pattern to be engraved on the horn surface. The welding strength of welded specimens was analyzed using a sawtooth pattern and lozenge-shaped pattern, and it was confirmed that the strength of the weld zone by welded for the sawtooth pattern was higher [24]. Lee [25] fabricated four kinds of horn-tip patterns by an analytical method and observed the loss of frictional energy. The influence of the shape of the pattern on the welded part was analyzed, and the pattern suitable for the purpose was selected and the ideas for the design modification were provided.

Thus, various attempts have been made to a method of effectively transferring the vibration energy to the base material according to the shape of various horns. The energy transferred through the horn-tip pattern forms an indentation mark on the surface of the base metal. A technique for evaluating the weldability according to the shape of the indentation mark is required. Detailed studies on the indentation marks on the surface of welds have not been conducted. The weldability evaluation technique using indentation mark can be used as a basic data for predicting weldability before welding failure test and selecting an appropriate horn-tip pattern according to physical properties of the base metal.

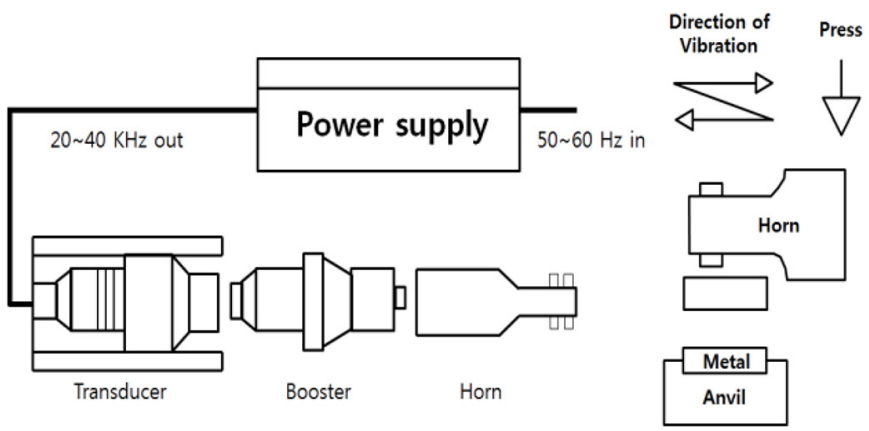

Fig. 1. Schematic diagram of ultrasonic metal welding (USMW).

In this study, four horn-tip patterns were designed for efficient transmission of vibration energy, and mechanical strength was evaluated after performing welding using two materials. In addition, the influence of each pattern was analyzed. In addition, the relationship between the indentations and the horn-tip pattern on the surface of the base material was analyzed, and the aspect ratio of indentation was adopted to investigate the correlation. The four patterns are different in the density of the square cones, and the two metals are chosen to compare the shapes of the indentations with different hardness. Experiments were carried out under various welding conditions and the relationship between indentation shapes was analyzed.

\section{Material and method}

\subsection{Experiment systems}

As shown in Figure 1, ultrasonic metal welding is a method in which two metals are welded by locally applying a highfrequency vibration of $20 \mathrm{kHz}$ or more to a base material. Ultrasonic waves are applied transversely parallel to the surface of the material for metal welding, and are applied in a longitudinal direction perpendicular to the material surface for welding plastic materials [26]. The ultrasonic metal welding system consists of a power supply, a converter, a booster and a horn. The electrical energy of $50-60 \mathrm{~Hz}$ supplied by the power supply is converted to mechanical vibration energy of $20000-40000 \mathrm{~Hz}$ by the converter. Minor vibrations are amplified to be used for metal welding. The friction heat generated by the vibration is transferred to the metal surface through the horn to destroy the oxide film and the contaminated film to form a metal-metal bond [27].

The ultrasonic welder used in the experiment is a Komax 2050 model with a frequency of $20 \mathrm{kHz}$ as shown in Figure 2A. The horn of the ultrasonic welder for metal has a pattern embossed on the surface as shown in Figure $2 \mathrm{~B}$ and designed to squeeze the welding material by the applied pressure. The three welding conditions are welding time, pressure and ultrasonic power, which can be individually adjusted via the controller as shown in Figure 2C.

The ultrasonic metal welding experiment was performed using four horn-pattern shapes and two materials. The two materials used in the experiment were representative nonferrous metals that are used for wire terminals 


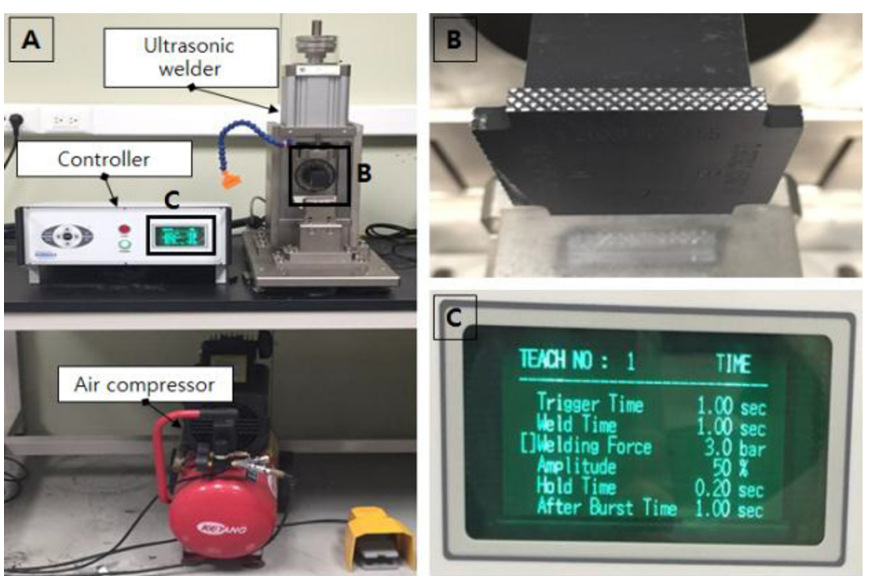

Fig. 2. Ultrasonic metal welding systems employed in the experiment; (A) systems configuration, (B) horn-pattern shape, (C) welding condition planner.

Table 1. Mechanical properties of base metal.

\begin{tabular}{llll}
\hline Material & Density & Yield strength & Hardness \\
\hline A1050 & 2.71 & 125.5 & 44 \\
C1220 & 8.94 & 246 & 99 \\
\hline
\end{tabular}

( $\mathrm{Cu}$ alloy) and light wire ( $\mathrm{Al}$ alloy). Table 1 shows the mechanical properties of the materials used in the experiment.

The two metals, which are very different in terms of hardness and density, allowed us to analyze the correlations of the horn-pattern and the material properties. Two nonferrous materials prepared for the experiment were industrial pure non-heat-treated 1xxx series aluminium alloy (purity 99.0-99.9\%) and deoxidized low-phosphorous copper. The $1 \mathrm{xxx}$ series aluminium alloy, usually used as a wire material, has a lower mechanical strength than other aluminium alloys but has good anti-corrosion property, light reflectivity, and electric and thermal conductivities with excellent processibility and weldability. The deoxidized low-phosphorous copper has a residual phosphorus content of $0.015-0.040 \%$ and shows a homogeneous microstructure in comparison with oxygen-free copper. The deoxidized low-phosphorous copper also has excellent ductility and fatigue strength, as well as good weldability.

As shown in Figure 3, the specimens used in the present study had the dimensions of $50 \mathrm{~mm} \times 100 \mathrm{~mm} \times 0.4 \mathrm{t}$ $(\mathrm{mm})$. The welding was performed by lap-joint welding. The surfaces of the welding specimens were cleaned by sequentially using a stainless wire-brush and \#400, \#800, and \#1500 sandpaper to prevent impurities including rust, scale, and oxides from causing a welding defect. After completing the welding, the indentation marks and the welding strength were evaluated.

\subsection{Pattern design on the horn}

The pattern inscribed on the tip of the horn transfers the vibrational energy and local pressure to a base welding material. Various horn-tip patterns may be used, but a quadrangular pyramid pattern is used for the welding of general metals. In ultrasonic metal welding, to induce a plastic flow of materials with the frictional heat, a longitudinal vibration (in a horizontal direction with overlapped materials) is applied. Therefore, a pattern should be inscribed to prevent the dislocation of the base material and to transfer the vibrational energy. In this study, the quadrangular pyramid pattern was designed in four different shapes.

Figure 4 shows the dimensions of the quadrangular pyramid pattern shapes and the images of the actual shapes. The four patterns are named A, B, C, and D, and pattern-A is ultra-fine with a pyramid height of $0.70 \mathrm{~mm}$. Pattern-B is a form in which the height of the pyramid $(\mathrm{H})$ is higher than the height of the pattern- $\mathrm{A}$ and the area of the bottom of the pyramid is widened, thereby increasing the pitch $(\mathrm{P})$ between the pyramids. Pattern- $\mathrm{C}$ is more coarse than pattern- $\mathrm{B}$, and pattern-D is Ultra-course. The pattern-D has the largest height of the pyramid and is $1.5 \mathrm{~mm}$.

The area of the embossed horn is $40 \mathrm{~mm} \times 5 \mathrm{~mm}$, and the pattern of the quadrangular pyramids is machined mechanically to prevent the base material from becoming a cave. Finally, the height of the stub tooth $(\mathrm{S})$ was reduced by $0.05 \mathrm{~mm}$ compared to the initial pyramid height $(\mathrm{H})$. The detailed dimensions of the four patterns are shown in Table 2.

\subsubsection{Welding condition}

The three welding conditions changed in this experiment are pattern shape, applied pressure and welding time. The same experimental conditions were used for both kinds of materials. To analyze the weldability depending on the applied pressure in each pattern, the welding time was fixed as $0.5 \mathrm{~s}$, and the pressure was increased from 1 to 6 bar in six levels. To analyze the weldability depending on the welding time, the applied pressure was fixed at 3 bar, and the welding time was increased from $0.1 \mathrm{~s}$ to $1.0 \mathrm{~s}$ in ten levels. The experiment was repeated 64 times for each material. Table 3 shows the welding parameters. Each experiment was performed with aluminium, aluminium, copper and copper as the same material welding experiment.

\section{Results and discussion}

\subsection{Indentation mark}

The embossed horn-tip is processed as a rough surface to prevent slippage between the horn and the base material during metal welding. The indentation marks on the specimen surfaces were dependent on the horn-pattern shapes. Figure 5 shows indentation marks formed on aluminium specimens and copper specimen surfaces after welding tests under the same welding conditions (welding time $0.5 \mathrm{~s}$, pressure 5 bar).

Figure 5A is an indentation mark formed on a copper joint, and Figure 5B is an aluminium joint. Comparing the two shapes, the indentation marks formed on the copper are more rhombic than those formed on aluminium. Under the same welding conditions, indentation marks are different depending on the properties of the 
Table 2. Specific dimensions of each horn-tip pattern

\begin{tabular}{llll}
\hline Pattern name & Pitch $(\mathrm{mm})$ & Height $(\mathrm{mm})$ & \multicolumn{2}{c}{ Stub tooth $(\mathrm{mm})$} \\
& $\mathrm{P}$ & $\mathrm{H}$ & $\mathrm{S}$ \\
\hline A (Ultra-fine) & 0.70 & 0.35 & 0.30 \\
B (Fine) & 0.90 & 0.45 & 0.40 \\
C (Coarse) & 1.2 & 0.60 & 0.55 \\
D (Ultra-coarse) & 1.5 & 0.75 & 0.70 \\
\hline
\end{tabular}

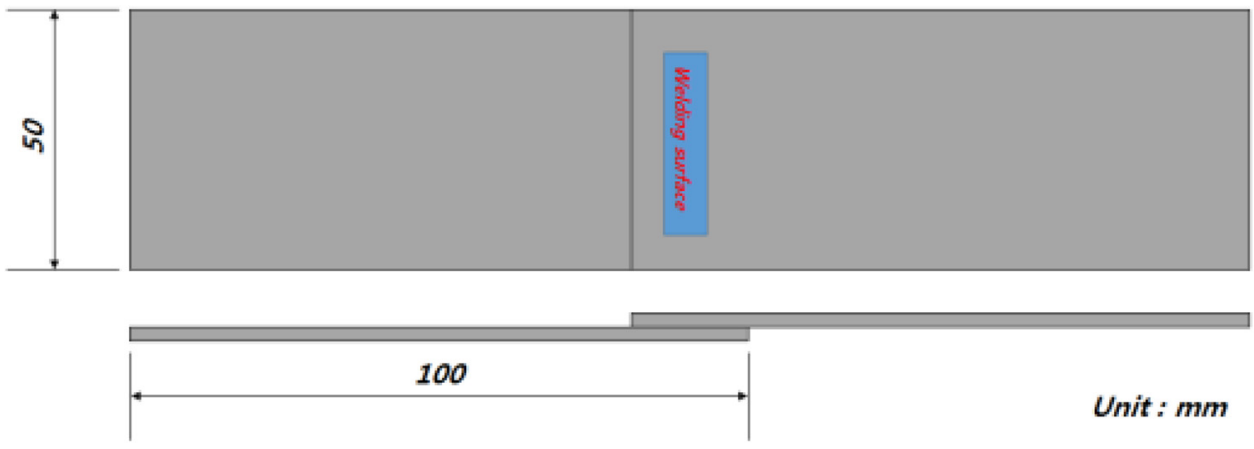

Fig. 3. Configuration of the welding specimen.
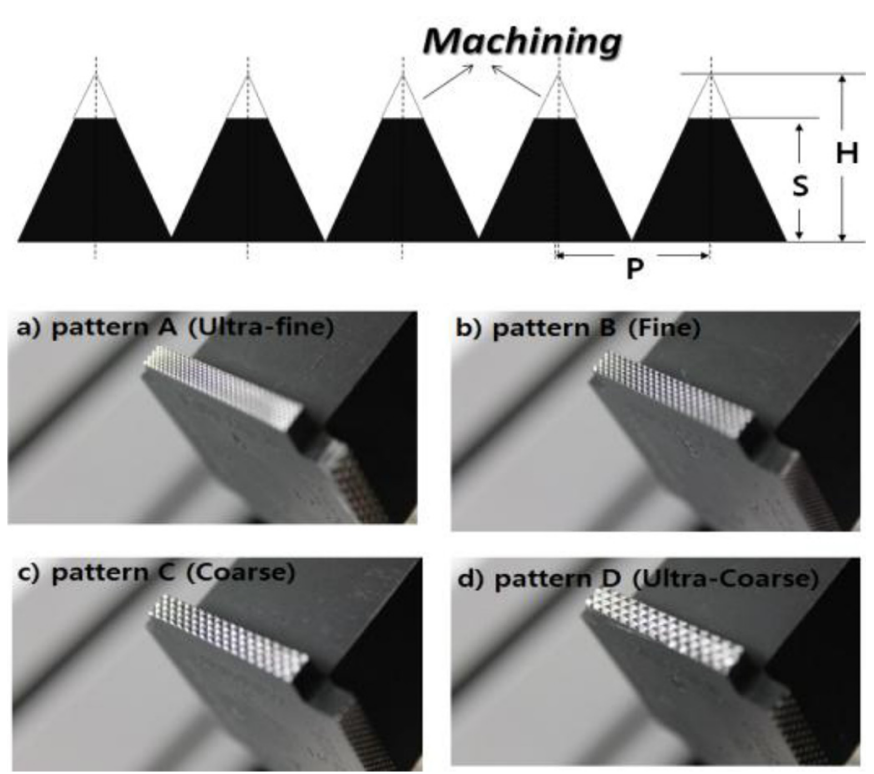

Fig. 4. Four horn-tip patterns used in the experiment.

metal, which is due to the mechanical properties of the two metals. The hardness of copper is $99 \mathrm{Hv}$, and the hardness of aluminum is $44 \mathrm{Hv}$, almost twice the difference, and the density is also three times higher. Indentation marks vary by pressure and vibration, and this provides a basis for understanding the transfer characteristics of energy.
Table 3. Welding parameters for USMW.

\begin{tabular}{llll}
\hline Term & & Conditions & level \\
\hline Material & & $\mathrm{Al}, \mathrm{Cu}$ & 2 \\
& Pattern & $\mathrm{A}, \mathrm{B}, \mathrm{C}, \mathrm{D}$ & 4 \\
Welding & Welding conditions & $1-6$ & 6 \\
conditions & $\begin{array}{l}\text { Pressure load (Bar) } \\
\text { Welding conditions }\end{array}$ & $0.1-1.0$ & 10 \\
& Welding time (sec) & & \\
\hline
\end{tabular}
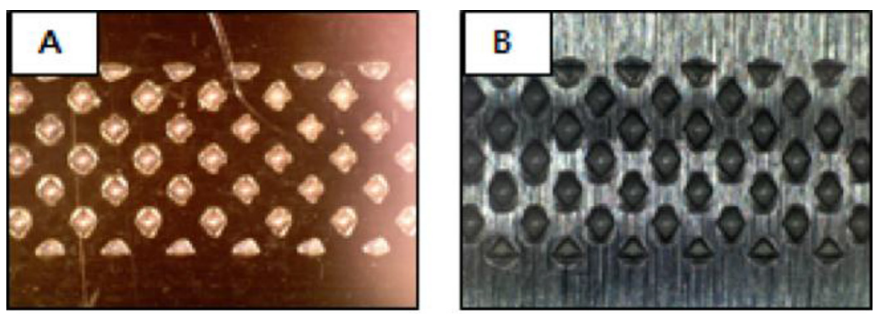

Fig. 5. Indention mark (a) material: copper, pattern: B, welding time: 0.5 , pressure: 5 bar, (b) material: aluminum, pattern: B, welding time: 0.5 , pressure: 6 bar.

Indentation marks are expressed in different forms depending on the welding material or according to the horn-tip pattern, and such phenomenon needs to be studied. For the detailed analysis of indentation marks, quantitative evaluation was carried out by adopting the concept of aspect ratio. As shown in Figure 6, quantitative data about the indentation marks were obtained to 


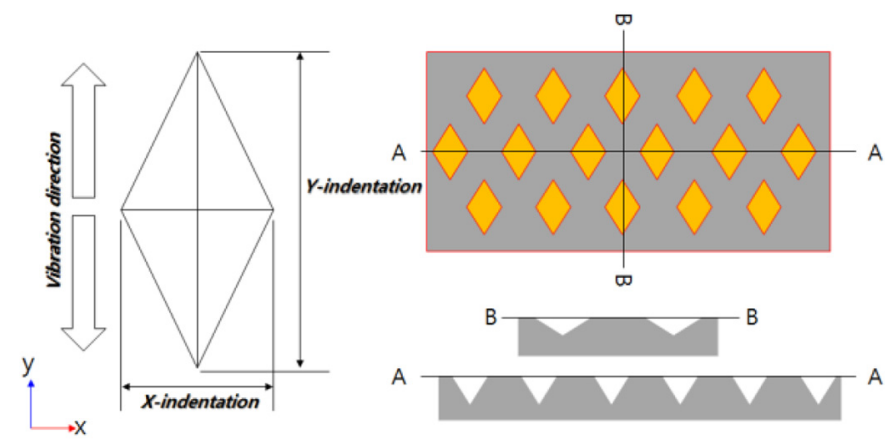

Fig. 6. Schematic diagram of indentation mark geometry.

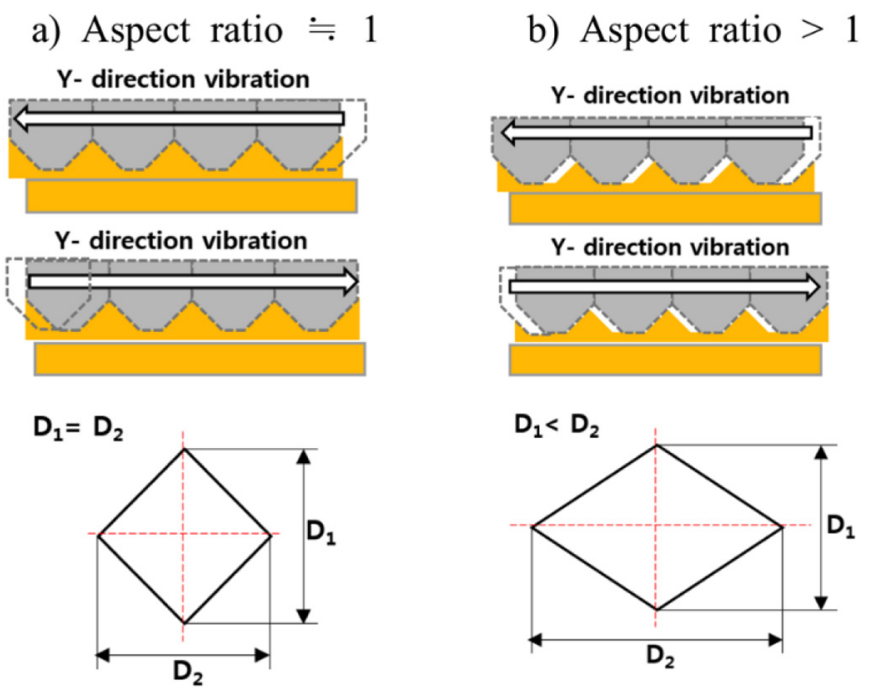

Fig. 7. Indentation marks caused by the transfer of vibration energy.

investigate the effect of the indentation marks on the quality of the welds. For the indentation marks, the length of the indentation in the vibration direction (Y-indentation) and in the width direction (Y-indentation) and the aspect ratio was calculated to analyze the characteristics of the welds. The aspect ratio, the ratio of the Yindentation to the $\mathrm{X}$-indentation, was calculated as shown in equation (1):

Aspect ratio $=\mathrm{X}$-indentation $/ \mathrm{Y}$-indentation (1)

As shown in Figure 7, one of the important roles played by the horn-tip pattern is to transfer the vibration energy to the base material. The aspect ratio is a result of the vibration energy transfer process. Inaccurate transfer of the horn vibration to the base materials means the loss of the vibration energy caused by a gap between the horn-tip pattern and the base material [28].

Figure 7A shows that the vibrational energy is mostly transmitted to the base material, the aspect ratio is close to 1 , and the indentation marks are similar to the square. Figure 7B shows the mechanism in which the indentation marks appear in rhombic form when the aspect ratio is greater than 1, and the vibration energy loss occurs due to the gap between the horn-pattern and the base metal.

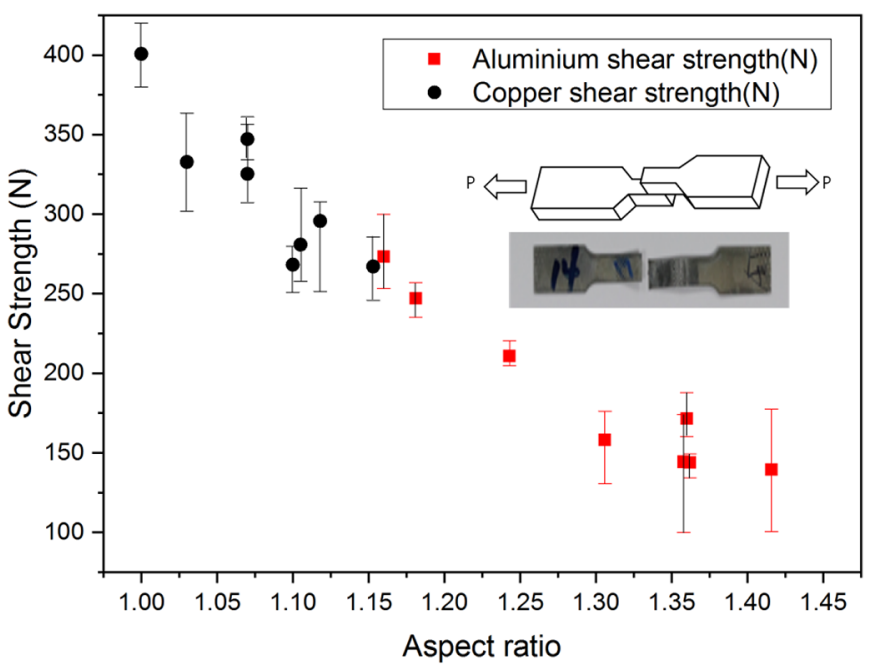

Fig. 8. Variation of shear strength with aspect ratio.

\subsection{Effect of aspect ratio for weld zone}

The mechanical properties were analyzed to investigate the effect of the aspect ratio on the weldability. A tensile shear test of the welds was performed to investigate the quantitative welding strength of the lap joint welded specimens, and to determine the appropriate strength of the welding method by examining the fractured parts of the specimens. The correlation between the aspect ratio and the welding strength was investigated by measuring the shear strength of the aluminium and copper welded specimens by ultrasonic metal welding.

Figure 8 shows the shear strength of the aluminium and copper materials measured at the ultrasonic welding zone, respectively. The black dot represents the shear strength of the copper, and the red square represents the shear strength of the aluminium. The result showed that the shear strength was higher at an aspect ratio closer to 1 . In addition, as the aspect ratio was increased, the shear strength was decreased. The maximum shear strength of the copper was about $400 \mathrm{~N}$ when the aspect ratio was close to 1 . However, at the aspect ratio of 1.15 , the shear strength was $225 \mathrm{~N}$, indicating that the aspect ratio has a significant effect on the weld strength. A similar result was found also in the aluminum material. Since the yield stress of the aluminum material was about half that of the copper, the shear strength was generally below $225 \mathrm{~N}$.

As described above, the aspect ratio may be considered as an indicator of the efficiency of the vibration energy transfer to the base material, and thus may serve as an important explanatory variable of weldability. An aspect ratio close to 1 indicates effective transfer of the vibration as well as efficient heat input by the contact friction between two base materials. Therefore, an aspect ratio close to 1 may help to obtain decent welds.

\subsection{Effect of Horn-tip pattern density}

Figure 9 shows the aspect ratio of the $\mathrm{Cu}$ and $\mathrm{Al}$ indentation marks depending on the horn-pattern shape. The height of the peaks in patterns $\mathrm{A}, \mathrm{B}, \mathrm{C}$, and D was 


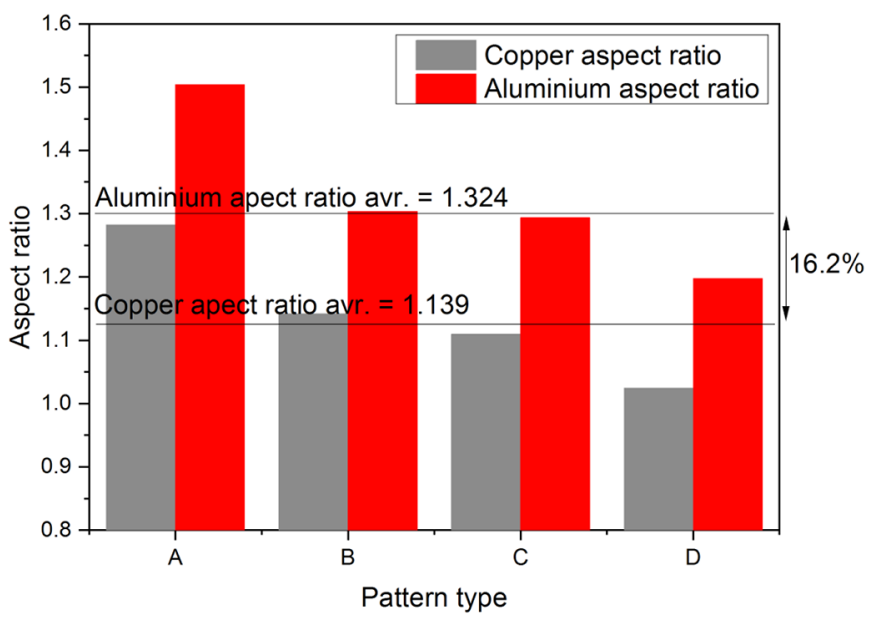

Fig. 9. Comparison of aspect ratio between copper and aluminum.

$0.7 \mathrm{~mm}, 0.9 \mathrm{~mm}, 1.2 \mathrm{~mm}$, and $1.5 \mathrm{~mm}$, respectively. The indentation mark size was averaged from the experiments performed with different horn-tip patterns. As indicated in Figure 9, the comparison of the indentation mark sizes depending on the pattern shapes shows that the indentation mark size $(x, y)$ was increased as the peak of the pattern was increased. The size of indentation marks as well as the indentation depth was increased as the pattern size in a unit area was increased and as the pattern density was decreased. The increase seen in the depth of the indentation mark as the pattern density was decreased was probably because the load applied to each peak was decreased. As described above, the indentation depth was increased as the pattern peak was increased. In addition, the aspect ratio was decreased as the pattern peak was increased. Therefore, as the aspect ratio was decreased, the indentation depth was increased, which increased the load applied to a unit area, increasing the interfacial friction between materials. In addition, the indentation mark size was also dependent on the mechanical properties of the welding materials, even when the same pattern shape was used. The hardness of copper is twice that of aluminum, and this difference in hardness might have caused the difference in the indentation marks. The comparison of the aspect ratio between the aluminum and copper materials having different hardness values showed that the average aspect ratio of the aluminum material was $1.324(16.2 \%$ higher) and that of the copper material was 1.139 . The aspect ratio of the aluminum material was over 1 in all the patterns.

\subsection{Effect of welding condition}

As described above, it was confirmed that the mechanical strength of the weld zone can be predicted by using the aspect ratio. However, before predicting welding quality, the controllable welding conditions should be prioritized to secure the ideal welding quality, because a strong factor in the welding quality may be selected as a basic control factor [29]. This study investigated the relationship between welding conditions (welding time, pressure, pattern type)

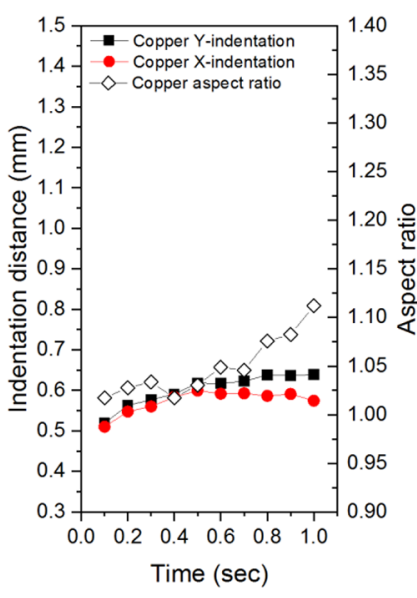

(A) Copper

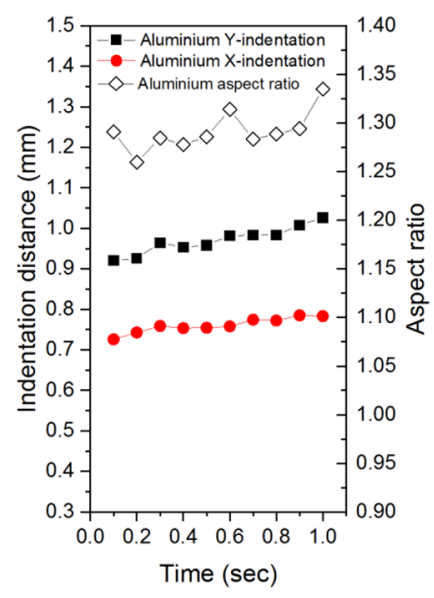

(B) Aluminium
Fig. 10. Variations of indentation length to welding time.

and aspect ratio which affect weld quality. As shown in Figure 10, welding time is the duration for which the vibration energy is continuously supplied to base metal. On the left side of Figure 10, the length of the X-indentation mark, the Y-indentation mark length and the aspect ratio identified in the copper specimens are plotted as the welding time increases. The right side of Figure 10 shows the results from the aluminum specimen, the left axis of each graph is the indentation distance, and the right axis represents the aspect ratio. As shown in Figure 10A, in the case of copper, the longer the welding time is, the more the $\mathrm{x}$-indentation marks and the $\mathrm{Y}$-indentation marks increase in length. The narrower the distance between the black line and the red line in the graph, the closer the aspect ratio is to 1. According to the above-mentioned research results, the probability that the quality of the weld is better as the aspect ratio approaches 1 increases, and it is confirmed that the aspect ratio becomes smaller as the welding time becomes shorter through this graph. As shown in Figure 10B, the aspect ratio of the aluminum specimen increased as the welding time increased, such as copper. Although the two materials used in the experiments differed in aspect ratio, the aspect ratio behavior was similar to the increase in welding time, which increased the aspect ratio. The aspect ratio of aluminum was not much changed compared with copper. This is confirmed by the slope of the line in which the aspect ratio is distributed. Figure 11 shows the change in aspect ratio according to the change of pressure according to the material. Figure 11A shows the change in the size and aspect ratio of the indentation mark of copper. In the case of copper, although the pressure increased from 0.3 to 6 bar, there was almost no change in the indentation mark shape. In case of copper, the indentation mark shape did not change even though the pressure increased from 0.3 to 6 bar, and there was no difference in aspect ratio.

It has become clear that the change in aspect ratio is caused by the shape of the horn-pattern. In order to change the aspect ratio, the shape of the pattern is most important, and the shape of the pattern is involved up to the compression depth of the base material. Figure 12 shows the $\mathrm{x}$-indentation, $\mathrm{y}$-indentation, and indentation depths 


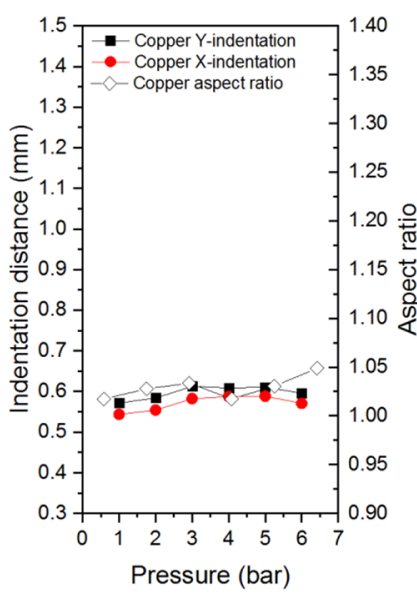

(A) Copper

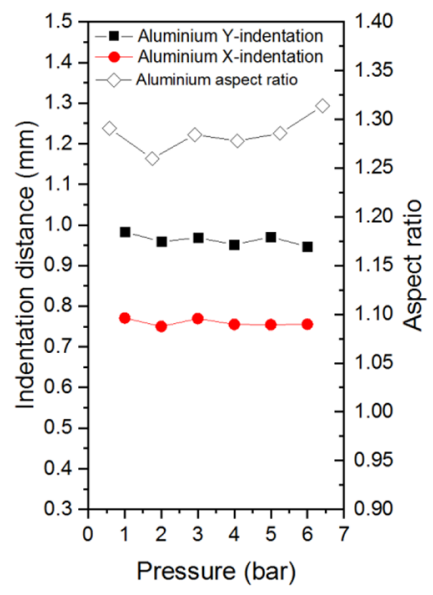

(B) Aluminium

Fig. 11. Variations of indentation length to welding time.

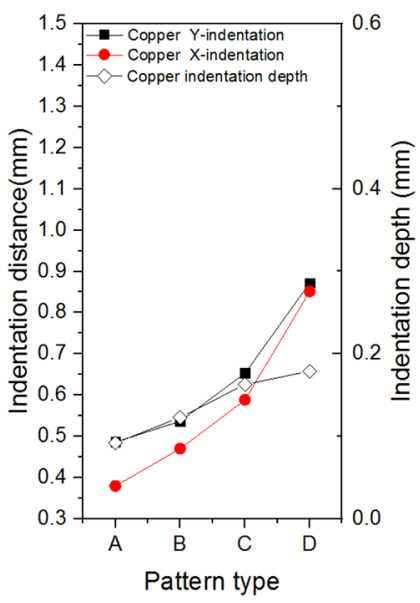

(A) Copper

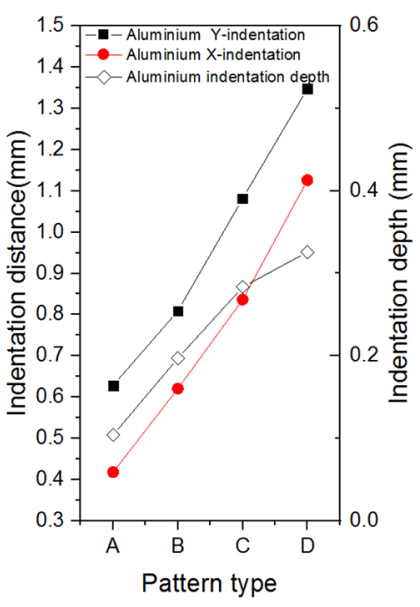

(B) Aluminium

Fig. 12. Variations of indentation length to pattern type.

of the pattern by dividing the pattern into A, B, C, and D. As the shape of the pattern becomes rougher (A to D), a large pressure is applied per unit area, and the indentation depth is deepened. The aspect ratio is correlated with the quality of the weld and should be selected as an item of visual inspection that can explain the quality of the weld.

The aspect ratio, which has not been considered in ultrasonic welding, has to be correlated with the quality of the weld and should be selected as an item of visual inspection that can explain the quality of the weld. According to the results of this study, it is desirable to minimize the welding time and to use the coarse pattern to make the aspect ratio close to 1 . However, if the welding time is minimized to reduce the aspect ratio to 1 , there is a risk that the welding zone will become cold-clad. It is necessary to control the aspect ratio close to 1 under the condition that the welding is completely performed.

\subsection{Hardness test}

As shown in Figure 13, the hardness was measured at the roof and valley of the indentation marks to investigate

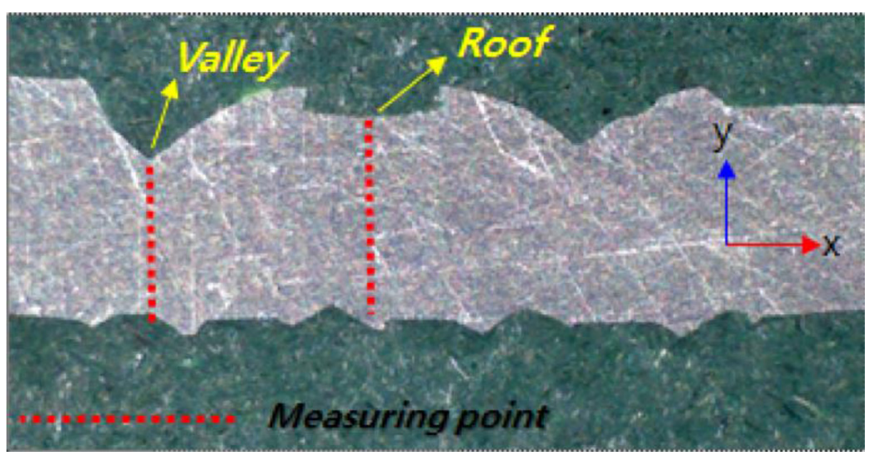

Fig. 13. Measurement of hardness in ultrasonic welded specimen.

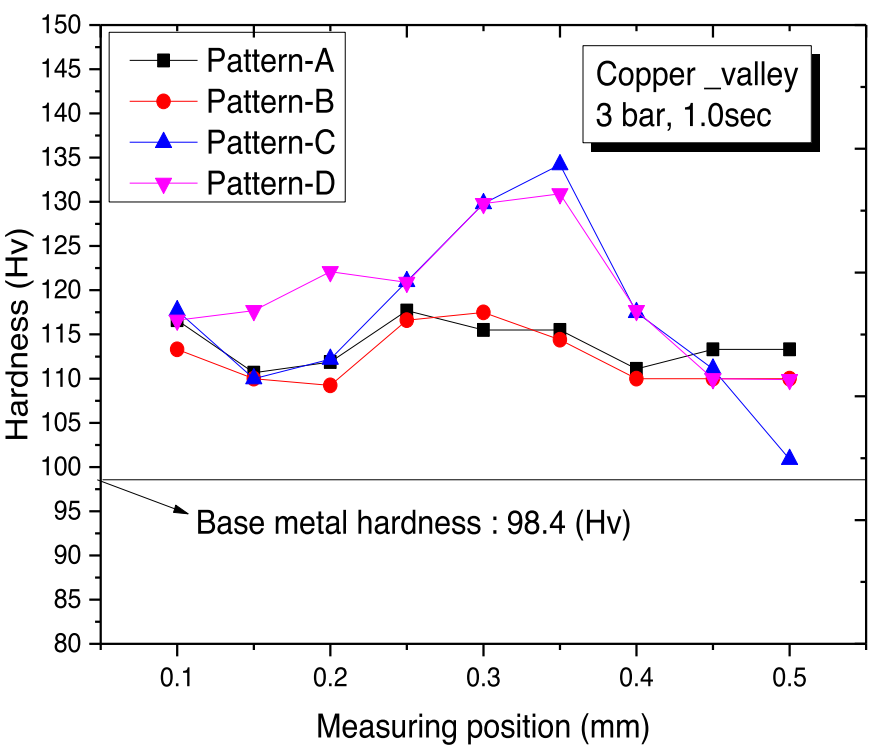

Fig. 14. Hardness curve at valley on cooper of specimen with pattern type.

the hardness of the welds depending on the horn-tip pattern shape. After measuring the indentation depth, the hardness of the welds was measured by applying a force of Hv0.05 (490.3 mN) with a Vickers hardness tester (Shimadzu, HMV-GT-21st). In ultrasonic welding, the hardness at the welds is increased by the plastic deformation of the base materials and the hardening by the frictional heat. The hardness of the welds may be used to determine the junction strength of the welds. The hardness of the aluminum and copper materials was measured and compared.

Figures 14 and 15 show the hardness of the welds of the copper materials. Figure 14 shows the weld hardness depending on the horn-tip pattern shapes after welding is performed with an applied pressure of 3 bar and a welding time of $1 \mathrm{~s}$. In comparison to the hardness value of the copper material $(98.4 \mathrm{Hv})$, the hardness was increased in all pattern shapes. The hardness was highest at the center of the valley where metal was stirred at the position of $0.3-0.4 \mathrm{~mm}$. Under the welding conditions of 6 bar and $0.5 \mathrm{~s}$, a similar trend was found. The weld hardness with the pattern shapes of $\mathrm{C}$ and $\mathrm{D}$ was over $125 \mathrm{Hv}$. 


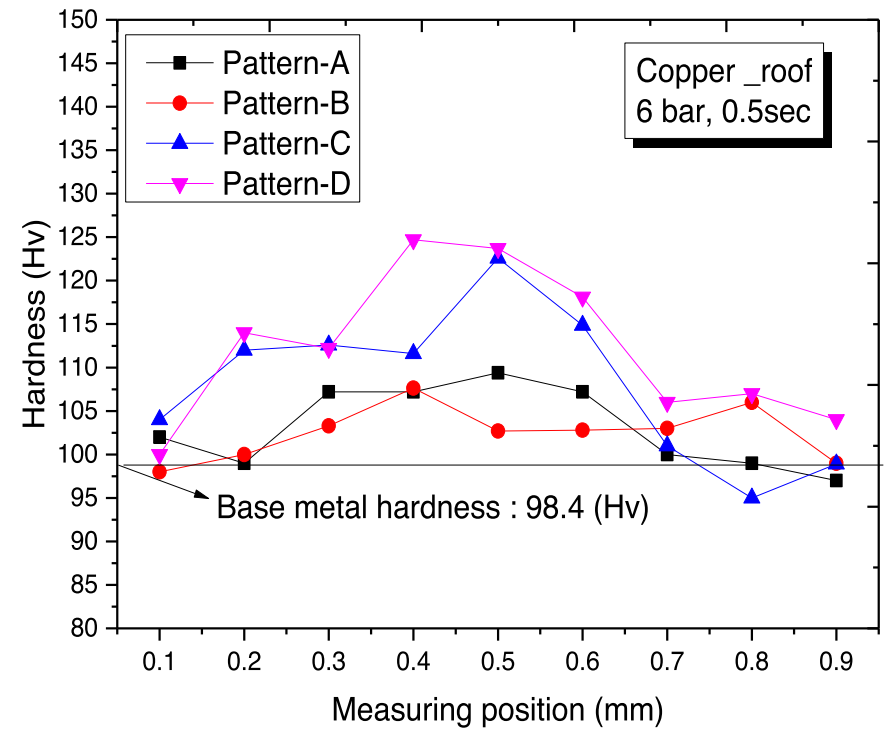

Fig. 15. Hardness curve at Roof on cooper of specimen with pattern type.

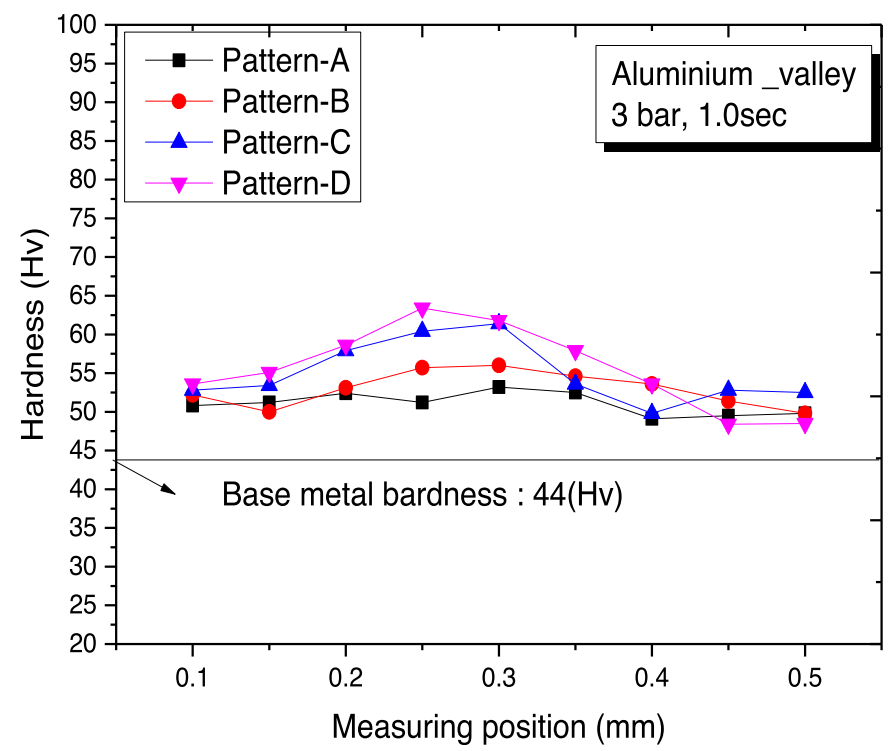

Fig. 16. Hardness curve at valley on aluminium of specimen with pattern type.

The hardness of the copper material at the roof showed a similar trend to the hardness at the valley. As the peak of the pattern was increased, the aspect ratio was increased and the weld hardness was increased, resulting in an increase in the weld strength. Figures 16 and 17 show the hardness of the aluminum material. The weld hardness of the aluminum material was $44 \mathrm{Hv}$, indicating that the material is very soft. Under the welding conditions of 3 bar and $1.0 \mathrm{~s}$, the hardness at the valley and the roof was generally higher than that of the base material in all the pattern shapes. The hardness at the stirred region was high because the interface of the base materials was stirred by the vibration of the horn after the base material was pressed to the horn-tip

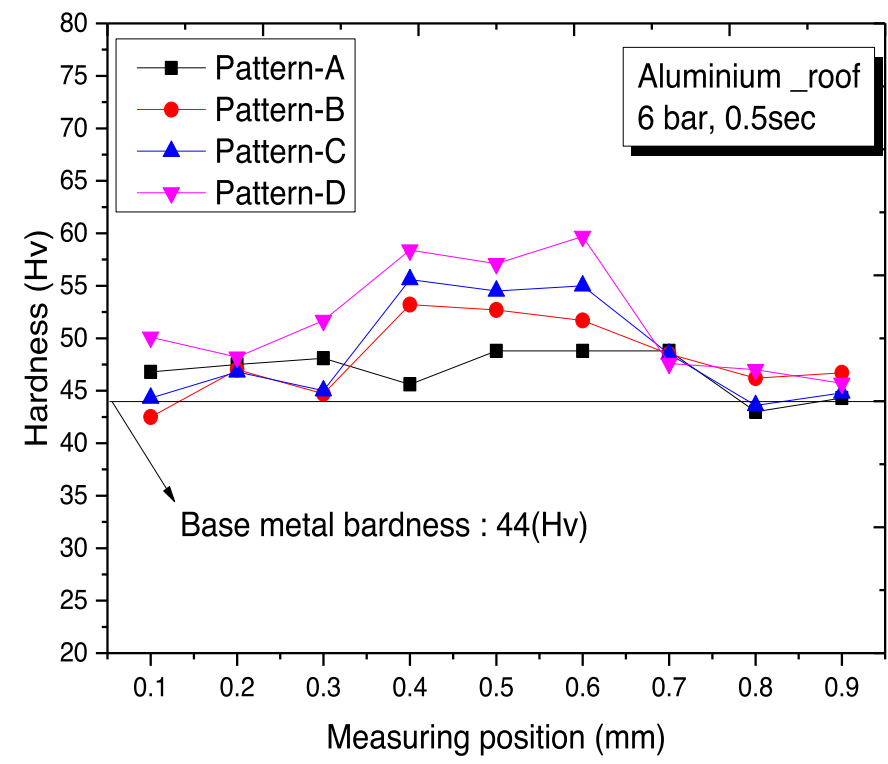

Fig. 17. Hardness curve at roof on aluminium of specimen with pattern type.

pattern. As the peak of the pattern shape was increased, the hardness at the welds was increased in the order of $\mathrm{A}<\mathrm{B}<\mathrm{C}<\mathrm{D}$.

\section{Conclusion}

In the present study, to compare the characteristics of ultrasonic metal welding depending on the horn-tip pattern, the indentation mark was defined with the aspect ratio. The experiment was performed with aluminum and copper materials. Indentation depth, hardness, and shear strength were analyzed depending on the indentation marks. The following conclusions were obtained from the results.

- Ultrasonic welding experiments were performed with aluminum and copper plates with the variables of horntip pattern, applied pressure, and welding time. The weld characteristics were analyzed using the aspect ratio of the indentation marks.

- The horn-tip pattern shape affected the aspect ratio of the indentation marks. The aspect ratio was also dependent on the material properties. An aspect ratio closer to 1 had a positive effect on the welds (better shear strength). In a departure from the conventional experience-based method of determining the pattern shapes, the aspect ratio of the indentation mark was suggested as an analytical reference, and the effect of the pattern shape on weldability was investigated. As a result, a protocol for determining the pattern shape depending on the ultrasonic welding target was proposed.

- To identify the major factors influencing the quality of ultrasonic welding, the effect of welding time, applied pressure, and horn-tip pattern shape on the indentation marks was investigated. It was found that the horn-tip pattern shape has the highest effect on the aspect ratio of the indentation marks. 
- The effect of the aspect ratio on the shear strength of the welds was investigated, and the correlation between the horn-tip pattern shape and the indentation mark aspect ratio was found. As the peak of the pattern was increased, the depth of the indentation mark was also increased. This was probably because the pattern density in a unit area of $40 \mathrm{~mm} \times 5 \mathrm{~mm}$ was decreased, and thus the load applied to the unit area was increased.

- As the peak of the pattern was increased, the hardness of the stirred region was increased, and the shear strength of the weld was also increased. The highest pattern peak means the lowest aspect ratio of the indentation mark, indicating that the decrease of the aspect ratio had a positive effect on the strength of the welds.

\section{References}

[1] N. Ahmed, New Developments in Advanced Welding, Woodhead Publishing, Australia, 2005

[2] J. Tsujino, T. Ueoka, K. Hasegawa, Y. Fujita, T. Shiraki, T. Okada, T. Tamura, New methods of ultrasonic welding of metal and plastic materials, J. Ultrasonics 34, 177-185 (1996)

[3] C. Zhang, M. Wu, J. Du, Improving weld quality by arcexcited ultrasonic treatment, J. Tsinghua Sci. Technol. 5, 475-478 (2001)

[4] N. Shen, A. Samanta, H. Ding, W.W. Cai, Simulating microstructure evolution of ultrasonic welding of battery tabs, J. Proc. Manufact. 5, 399-416 (2016)

[5] Z.L. Ni, F.X. Ye, Weldability and mechanical properties of ultrasonic welded aluminum to nickel joints, J. Mater. Lett. 185, 204-207 (2016)

[6] E.A. Neppiras, Ultrasonic welding of metals, J. Ultrasonic 3, 128-135 (1965)

[7] H. Potente, Ultrasonic welding - principles \& theory, J. Mater. Des. 5, 228-234 (1984)

[8] Z. Jingzhou, L. Hang, C. Hongseok, C. Wayne, J.A. Abell, L. Xiaochun, Insertable thin film thermocouples for in situ transient temperature monitoring in ultrasonic metal welding of battery tabs, J. Manufactur. Process. 15, 136140 (2013)

[9] I.E. Gunduz, T. Ando, E. Shattuck, P.Y. Wong, C.C. Doumanidis, Enhanced diffusion and phase transformations during ultrasonic welding of zinc and aluminum, J. Scr. Mater. 52, 939-943 (2005)

[10] G. Harman, J. Albers, The ultrasonic welding mechanism as applied to aluminum-and gold-wire bonding in microelectronics, J. IEEE Trans. Parts 13, 406-412 (1977)

[11] Z.L. Ni, F.X. Ye, Weldability and mechanical properties of ultrasonic welded aluminum to nickel joints, J. Mater. Lett. 185, 204-207 (2016)
[12] M.P. Satpathy, S.K. Sahoo, Mechanical performance and metallurgical characterization of ultrasonically welded dissimilar joints, J. Manufact. Process. 25, 443-451 (2017)

[13] D. Ren, K. Zhao, M. Pan, Y. Chang, S. Gang, D. Zhao, Ultrasonic spot welding of magnesium alloy to titanium alloy, J. Scr. Mater. 126, 58-62 (2016)

[14] Z.L. Ni, F.X. Ye, Weldability and mechanical properties of ultrasonic welded aluminum to nickel joints, J. Mater. Lett. 185, 204-207 (2016)

[15] H. Li, B. Cao, J.W. Yang, J. Liu, Modeling of resistance heat assisted ultrasonic welding of $\mathrm{Cu}-\mathrm{Al}$ joint, J. Mater. Process. Technol. 256, 121-130 (2018)

[16] Z. Lei, J. Bi, P. Li, T. Guo, Y. Zhao, D. Zhang, Analysis on welding characteristics of ultrasonic assisted laser welding of AZ31B magnesium alloy, J. Optics Laser Technol. 105, 15$22(2018)$

[17] A.A. Ward, Y. Zhang, Z.C. Cordero, Junction growth in ultrasonic spot welding and ultrasonic additive manufacturing, J. Acta Mater. 158, 393-406 (2018)

[18] M.R. Sriramana, M. Gonsera, H.T. Fujiia, S.S. Babua, M. Blossb, Thermal transients during processing of materials by very high power ultrasonic additive manufacturing, J. Mater. Process. Technol. 211, 1650-1657 (2011)

[19] W. Wu, J. Jiang, G. Li, J.Y. Fuh, H.H. Jiang, P. Gou, Ultrasonic additive manufacturing of bulk Ni-based metallic glass, J. Non-Cryst. Solids 506, 1-5 (2019)

[20] S. Kumar, C.S. Wu, G.K. Padhy, W. Ding, Application of ultrasonic vibrations in welding and metal processing: a status review, J. Manufact. Processes 26, 295-322 (2017)

[21] M. Carboni, Failure analysis of two aluminium alloy sonotrodes for ultrasonic plastic welding, J. Fatigue 60, 110-120 (2014)

[22] B.G. Lee, M.S. Oh, J.B. Ma, Design of ultrasonic tool horn for wire wedge bonding, J. Korean Soc. Manufact. Technol. Eng. 22, 717-722 (2013)

[23] S.R. Kim, J.H. Lee, C.D. Yoo, Design of bar horn for ultrasonic bonding, J. KWJS 27, 68-73 (2009)

[24] K. Komiyama, T. Sasaki, Y. Watanabe, Effect of tool edge geometry in ultrasonic welding, J. Mater. Process. Technol. 229, 714-721 (2016)

[25] D. Lee, W. Cai, The effect of horn knurl geometry on battery tab ultrasonic welding quality: 2D finite element simulations, J. Manufactur. Process. 28, 428-441 (2017)

[26] A.P. Hulst, Macrosonics in industry 2. Ultrasonic welding of metals, J. Ultrasonics 10, 252-261 (1972)

[27] H.P. Daniels, Ultrasonic welding, J. Ultrasonic 3, 190-196 (1965)

[28] R. Jahn, R. Cooper, D. Wilkosz, The effect of anvil geometry and welding energy on microstructures in ultrasonic spot welds ofAA6111-T4, J. Metal. Mater. Trans. A 38, 570-583 (2007)

[29] K.Y. Benyounis, A.G. Olabi, Optimization of different welding processes using statistical and numerical approaches - a reference guide, J. Adv. Eng. Softw. 39, 483-496 (2008)

Cite this article as: J. Kim, J. Kim, I. Kim, Analysis of welding properties using various horn-tip patterns in the ultrasonic metal welding process, Mechanics \& Industry 21, 102 (2020) 